\title{
Testing and initial verification of the world's first metal 3D printed bridge
}

\author{
Leroy Gardner, Pinelopi Kyvelou, Gordon Herbert and Craig Buchanan
}

Imperial College London

\begin{abstract}
Wire and arc additive manufacturing (WAAM) is a method of metal 3D printing that is suited to the requirements of the construction industry in terms of scale, speed and cost. Using this technology, a $10.5 \mathrm{~m}$ span footbridge, the first of its kind, has been printed. The testing, analysis and initial verification of the bridge and its components are described herein. The experiments performed included advanced geometric analysis, material testing, compressive testing of crosssections and full-scale load testing of the bridge at various stages throughout and post construction. Parallel finite element modelling of the full bridge and its constituent elements has also been performed as part of the verification. Confirmation that the bridge was able to sustain its full serviceability design load enabled to the bridge to be unveiled to the public, with controlled access, for Dutch Design Week 2018. Further testing under ultimate limit state design loading is planned before the bridge is placed in its final location and fully opened to the public. The project highlights the potential for metal 3D printing in structural engineering, as well as the necessary considerations for design.
\end{abstract}

Keywords: 3D printing; Finite element modelling; Steel structures; Stability; Testing; Wire and arc additive manufacturing. 


\section{INTRODUCTION}

Having already gained traction in other sectors, metal 3D printing has now reached the construction industry [1-8]. Wire and arc additive manufacturing (WAAM) [9] is a method of metal 3D printing that enables large components to be built with reasonable geometric accuracy, costs and build times; this technology has been used to create the world's first 3D printed metal bridge, the testing and initial verification of which are described in this paper. Overall and plan views of the bridge are shown in Figures 1 and 2.

The bridge was constructed by the Dutch company MX3D, built up in a series of layers of weld material in two nominal thicknesses $(3.5 \mathrm{~mm}$ from the handrails and $8.0 \mathrm{~mm}$ for the sub-structure) that ran transversely to the longitudinal axis of the bridge elements, as can be seen in Figure 3 . The bridge was printed in four main pieces, plus the four corner swirls, which were then manually welded together. The manual welds were located at approximately the midspan and quarter points of the bridge and can be observed from close inspection of Figure 1. Printing was carried out using a 6-axis $\mathrm{ABB}$ industrial robot, fitted with a MIG welding machine, as shown in Figure 4, and controlled using MX3D's software. In Figure 4, the robot is mounted on the bridge for demonstration purposes, though the majority of printing was performed with the robot groundmounted and a vertical build direction. The feedstock material for the printing was Grade 308LSi austenitic stainless steel wire, with over $1100 \mathrm{~km}$ of wire used. The current and arc voltage employed during the deposition process were 100-140 A and 18-21 V respectively, while the deposition rate was generally $0.5-2.0 \mathrm{~kg} / \mathrm{h}$. For the bridge elements of $3.5 \mathrm{~mm}$ nominal thickness, wire of $1.0 \mathrm{~mm}$ diameter was deposited with a welding speed of $15-30 \mathrm{~mm} / \mathrm{s}$ and a wire feed rate of $4-8 \mathrm{~m} / \mathrm{min}$; for the bridge elements of $8.0 \mathrm{~mm}$ nominal thickness, wire of $1.2 \mathrm{~mm}$ diameter was used with a welding speed and wire feed rate of $13 \mathrm{~mm} / \mathrm{s}$ and $5.7 \mathrm{~m} / \mathrm{min}$ respectively. The bridge has an overall mass of 7.8 tonnes, of which, approximately 4.6 tonnes was printed. The non-printed 
components comprise cold-formed stainless steel (grade 304L) rectangular hollow sections (RHS), forming the end beams, hot-rolled stainless steel (grade 316L) plate, forming the deck, both of which were manually welded to the $3 \mathrm{D}$ printed sub-structure, and a non-slip deck coating. The bridge has an overall length of $12.5 \mathrm{~m}$, a span of $10.5 \mathrm{~m}$ and an average width of $2.5 \mathrm{~m}$. Printing was spread over a period of about six months; structural testing was undertaken both within and subsequent to the printing period, as described herein.

Testing has been performed at the material level through tensile coupon tests, as reported in Section 2 of this paper, at the cross-section level through stub column tests, as described in Section 3, and at the structural level through full-scale load testing of the complete bridge, as outlined in Section 4. Advanced finite element modelling of the bridge and its components has also been performed, as outlined in Section 5. The finite element model of the full bridge featured the overall geometry, imported from the CAD file from which the bridge was printed, as well as the material properties obtained from the tensile testing. Verification of the bridge involved a combination of traditional structural design calculations, full scale physical testing and nonlinear finite element modelling, as described in Section 6.

\section{MATERIAL TESTING}

In order to determine the material stress-strain characteristics of the bridge, a comprehensive series of tensile material tests performed on coupons cut from flat plates printed using the same feedstock material and printing parameters as the bridge, was undertaken [10]. Two types of tensile coupon were prepared - 'undulating' coupons with the as-built geometry and 'smoothed' coupons with a machined uniform prismatic cross-section within the reduced region; as-built and smoothed surfaces of a typical WAAM plate are shown in Figure 5(a). In both cases, tests were performed on material extracted at $0^{\circ}, 45^{\circ}$ and $90^{\circ}$ to the print layer direction, as defined in Figure 5(b). 
The coupon tests were undertaken in compliance with EN ISO 6892-1 [11]. The load cell within an Instron 8802 testing machine measured the applied tensile load. A four camera LaVision digital image correlation (DIC) system was used to measure the surface strain field on both sides of the coupons. A random paint speckle pattern was applied, and the strains were calculated using a virtual strain gauge placed over the full area of the parallel length. The DIC system acquired images at a frequency of $1 \mathrm{~Hz}$. As recommended in EN ISO 6892-1 [11] two strain rates were used - a slower rate of $0.00007 \mathrm{strain} / \mathrm{sec}$ before yielding and a faster rate of $0.00025 \mathrm{strain} / \mathrm{sec}$ post yield, with a gradual transition ramp between them.

Six typical measured stress-strain curves from the machined coupon tests on the nominally $8 \mathrm{~mm}$ thick material are plotted in Figure 6, while the average values of Young's modulus $E, 0.2 \%$ proof stress $\sigma_{0.2}, 1.0 \%$ proof stress $\sigma_{1.0}$, ultimate tensile stress $\sigma_{\mathrm{u}}$, strain at the ultimate tensile stress $\mathcal{E}_{\mathrm{u}}$, fracture strain measured over the standard gauge length $\varepsilon_{\mathrm{f}}[11]$, the Ramberg-Osgood parameter $n$ $[12,13]$ and the extended parameters $m_{1.0}$ (previously referred to as $n_{0.2,1.0}^{\prime}$ ) and $m_{\mathrm{u}}$ (previously referred to as $n_{0.2, \mathrm{u}}$ ) [14-17], are reported in Table 1 (grouped by printing direction - i.e. $0^{\circ}, 45^{\circ}$ and $\left.90^{\circ}\right)$. The coupon designation system starts with the type of specimen $(\mathrm{M}=$ machined; $\mathrm{AB}=\mathrm{as}-$ built), followed by the nominal thickness in $\mathrm{mm}$ and the orientation relative to the print layer direction in degrees; the final part of the label contains a letter that refers to the plate from which the coupon was taken and a number to identify each coupon. Note that the Ramberg-Osgood and extended parameters were determined using a weighted total least squares regression method that is independent of the distribution of the data points $[17,18]$ - a more detailed description can be found in [10]. 
The results from the three tested orientations demonstrate an inherent material anisotropy, as apparent from Figure 6 and Table 1. The coupons tested in the $90^{\circ}$ orientation had the lowest $0.2 \%$ proof stress $\sigma_{0.2}, 1.0 \%$ proof stress $\sigma_{1.0}$ and ultimate tensile strength $\sigma_{\mathrm{u}}$, which can be expected since the material is being loaded across the individual layers. The coupons tested in the $0^{\circ}$ and $90^{\circ}$ directions had the lowest Young's moduli, with the values observed being about 25\% lower than the typically assumed value of $E=200000 \mathrm{~N} / \mathrm{mm}^{2}$ for stainless steel. The coupons tested in the $45^{\circ}$ orientation exhibited a significantly higher Young's modulus and a slightly higher strength than the other tested orientations. The strength and ductility of all the tested 3D printed material is generally similar to that observed in conventionally produced material. It should be mentioned that the observed anisotropy has been linked to the internal microstructure of the printed material, which was found to exhibit a strong crystallographic texture owing to the thermal gradients associated with the WAAM process $[5,10]$.

For the undulating as-built coupons, six typical measured stress-strain curves for the nominally 8 mm thick material are shown in Figure 7, while a summary of the key average material properties is shown in Table 2. Note that the stresses were calculated based on the mean cross-sectional area $A_{\text {laser }}$ of the coupons, as determined through 3D laser scanning [10], further details of which are presented in Section 3. Clearly the stress-strain curves of the as-built material are influenced by the variability of the geometry of the coupons; the derived material properties should therefore be considered as 'effective' material properties. Relative to the machined coupons, the as-built coupons generally exhibited lower values of Young's modulus and strength, by up to about 20\%, due to the undulating geometry. 


\section{COMPONENT TESTING}

\subsection{Introduction}

The compressive structural response of the key components of the bridge was assessed by means of stub column testing. Stub columns of similar proportions to the key bridge elements i.e. similar width- or diameter-to-thickness ratios (see Figure 8), but with more regular geometry, were built. The geometric regularity (i.e. square hollow sections (SHS) and circular hollow sections (CHS)) enabled the differences in structural response of the $3 \mathrm{D}$ printed sections relative to equivalent traditionally manufactured sections to be isolated and evaluated.

Four tests were performed for each hollow section type-SHS and CHS, with two different nominal wall thicknesses and a repeat specimen tested for each permutation. The two different nominal wall thicknesses provided variation in the local cross-section slenderness and hence allowed the influence of local buckling to be assessed, while the repeated tests enabled the variability in response to be evaluated. The nominal section sizes were $120 \times 120 \times 8$ (outer width $\times$ outer breadth $\times$ thickness) and $130 \times 130 \times 3.5$ SHS and $105 \times 8$ (outer diameter $\times$ thickness) and $170 \times 3.5$ CHS, covering cross-section classes 1-4 according to the EN 1993-1-4 [19] slenderness limits. The specimen notation is illustrated by the following example: $105 \times 8-355-\mathrm{F}$ is a $105 \times 8$ cross-section with a $355 \mathrm{~mm}$ nominal length with ' $\mathrm{F}$ ' indicating fixed end conditions; a specimen ending with ' $R$ ' denotes a repeat test.

\subsection{Geometric measurements}

The geometric properties of the CHS and SHS specimens were measured prior to testing. Detailed measurements of geometry are of particular importance for WAAM specimens due to the variation in wall thickness and surface profile. A number of techniques were employed, including hand calliper, Archimedes' principle, digital image correlation (DIC), 3D laser scanning and CT 
scanning measurements, though the laser scanning and Archimedes approaches are considered to be the most practical and accurate, and the measurements obtained by these means are hence reported herein.

Archimedes' principle, where the buoyant force on a submerged object is equal to the weight of water displaced by that object, was employed to determine the volume of the stub columns. This principle is commonplace in concrete research to determine porosity, where it is typically called the water displacement method [20]. Having obtained the volume of the specimens, the mean crosssectional area $A_{\text {Arch }}$ was determined by dividing through by the member length $L$, obtained using callipers.

Laser scanning was also employed to measure the complete external and internal surface geometry of the stub columns. A Faro ScanARM was used to scan the outside of the specimens, along with a portion (around $10-20 \%$ of the specimen length) of the specimen interior; further scanning of the inner surface was inhibited due to the size of the scanning arm head, as apparent from Figure 9(a). A direct silicone cast of the inside geometry was therefore also made, laser scanned and combined with the original scan. A combined scan of a $105 \times 8$ CHS specimen is shown in Figure 9(b). The scan was then converted into a polygon mesh using Geomagic Wrap [21] and imported into Rhinoceros [22] to calculate the geometric properties. The differences in mean cross-sectional areas obtained from Archimedes' principle $A_{\text {Arch }}$ and laser scanning $A_{\text {laser }}$ were less than $3 \%$.

\subsection{Testing}

The stub column test setup for the CHS specimens is shown in Figure 10. An Instron 3500kN-SPL testing machine was used. The instrumentation for the CHS tests consisted of three electrical resistance strain gauges (affixed to a flat surface formed from PS adhesive) equally spaced around 
the circumference of the specimens at mid-height, three equally spaced linear variable displacement transducers (LVDT) to measure the vertical movement of the top platen of the testing machine and a load cell within the machine to measure the applied load. A self-locking spherical head was used to ensure full contact between the stub column ends and the end platens. A similar setup was employed for the SHS tests, but with four strain gauges attached to the specimens at mid-height on opposite faces and four LVDTs used to measure the top platen movement - this setup has also been used for previous SHS stub column tests [2,23]. Non-contact digital image correlation (DIC) measurements were also taken using a two camera LaVision DIC system, allowing surface deformations to be recorded and strains computed. The testing machine displacement (imposed at a rate between 0.2 and $0.5 \mathrm{~mm} / \mathrm{min}$ ) and applied load were recorded simultaneously with the image acquisition through an analogue-to-digital (A/D) convertor. The tests were continued beyond the ultimate load to observe the initial unloading behaviour. The DIC system acquired data at $0.1 \mathrm{~Hz}$, while the datalogger for the strain gauges, LVDTs and load cell was recording at $2 \mathrm{~Hz}$.

\subsection{Results}

Load-end shortening curves were determined (i) using the LVDT and strain gauge data, with the deformation of the end platens removed [24], and (ii) directly from the DIC deformation data, by exporting and subtracting vertical displacements at the two ends of the stub columns, near the end platens. These curves are plotted in Figure 11 and show that the results from the two approaches are essentially identical.

The EN 1993-1-4 [19] compressive cross-section classes, local slendernesses $\left(D / t \varepsilon^{2}\right.$ and $c / t \varepsilon$ for the CHS and SHS respectively, where $D$ is the mean diameter of the CHS, $c$ is the mean flat width of the faces of the SHS, $t$ is the mean thickness and $\left.\varepsilon=\left[\left(235 / \sigma_{0.2}\right)(E / 210000)\right]^{0.5}\right)$ with $\sigma_{0.2}$ and $E$ based on the measured properties from the machined coupons in the $90^{\circ}$ direction, ultimate axial 
load $N_{\mathrm{u}}$, end shortening at the ultimate load, from the LVDTs and strain gauges $\delta_{\mathrm{u}, \mathrm{LVDT}}$ and separately from the DIC $\delta_{\mathrm{u}, \mathrm{DIC}}$, and ultimate load normalised by the yield load, $N_{\mathrm{u}} / N_{\mathrm{y}}$ with the yield load calculated as $N_{\mathrm{y}}=A_{\text {laser }} \sigma_{0.2}$ based on the mean area recorded from the laser scan, are reported in Tables 3 and 4, for the CHS and SHS stub columns respectively. The two stockier class 1 crosssections exhibited a higher degree of variation in ultimate load (almost 30\% for the CHS and 20\% for the SHS) than for conventionally formed cross-sections, highlighting the influence of the initial geometry, and potentially residual stresses, on the structural response. The more slender crosssections displayed a lower variation in peak load - around $5 \%$ for both cross-section types. The normalised yield loads show that the class 1 CHS specimens underwent significant strain hardening, while the class 1 SHS specimens underwent modest strain hardening.

Comparisons are also made against the resistance predictions $N_{\mathrm{u}, \mathrm{EC} 3}$ calculated using EN 1993-1-4 [19], based on mean measured properties. The results show that while the resistance predictions for the stockier sections are generally on the safe side due to strain hardening (which is not captured in the EC3 calculations), the resistances of the more slender sections are overpredicted by the current design provisions. This reflects primarily the greater geometric variability associated with the WAAM cross-sections relative to hot-rolled and cold-formed sections, and highlights the need for design provisions that are specific to this form of manufacture. The general behaviour does however accord with the anticipated trend of reducing normalised capacity with increasing local slenderness.

The deformed CHS and SHS stub columns are shown in Figure 12. The CHS deformed shapes are different to conventionally formed CHS, with the buckled shapes generally resembling an amplification of its initial imperfection, while the SHS deformed shapes are more akin to the classical 'in-out' local buckling. 


\section{LOAD TESTING OF BRIDGE}

\subsection{Introduction}

Full-scale in-situ structural load testing was undertaken on the MX3D bridge, at the MX3D facility in Amsterdam, the Netherlands by the authors at various stages of its construction. The testing served to verify the structural performance of the bridge and was used for validation of the finite element model. The first $2.4 \mathrm{~m}$ of handrail and substructure were initially tested; then the complete substructure and handrails but without the deck were tested and finally, the complete bridge with the deck welded in place was tested up to the serviceability limit state design load. Both vertical and horizontal load cases were considered. A final round of structural testing will be undertaken before the bridge is placed in the centre of Amsterdam. This section outlines the purpose of these structural tests, the types of tests carried out, the instrumentation used and the results obtained.

A variety of sensors and instrumentation were employed during the bridge testing. Load cells were incorporated into the horizontal loading props, to measure the load applied to the handrails, and positioned beneath the bridge on hemispherical bearings, to measure self-weight and applied vertical load. Horizontal and vertical displacements were measured at a series of locations using linear variable differential transducers (LVDTs) and string potentiometers. Inclinometers were attached to the top of the handrails and the end support beams to measure rotations. Strain gauges were affixed to the substructure, end beams and handrails to measure local strains at key locations. Finally, digital image correlation techniques were used to monitor the three dimensional deformation of a $3 \mathrm{~m}$ length of handrail during testing of the complete bridge.

\subsection{Testing of first $2.4 \mathrm{~m}$ segment of bridge}

Once the first $2.4 \mathrm{~m}$ segment of the bridge had been printed, preliminary testing was undertaken to verify the performance of the bridge and to provide initial validation of the finite element model 
described in Section 5. Two types of test were performed - vertical loading to the substructure and horizontal loading to the handrails (see Figures 13 and 14). The test results were in satisfactory agreement with those predicted by the numerical model, providing confidence in the consistency and integrity of the building process.

\subsection{Testing of full bridge without deck}

The full bridge, both with and without the deck plate welded in place, was subjected to a series of horizontal and vertical loading scenarios. Testing of the full bridge without the deck is described in this sub-section. Vertical loading was applied by means of four $1 \mathrm{~m}^{3}$ water tanks up to a load level of 4 tonnes. Horizontal handrail loading was applied at three locations through loading props, as shown in Figure 15. The loading props were designed and fabricated in the Structures Laboratory at Imperial College London. Each prop was fabricated from two lengths of square hollow section (SHS) with midspan splice plates to facilitate transportation to the Netherlands. A loading jack, load cell and ball seating were incorporated into each prop, which could be configured to apply either inward and outward point loads to the handrails. The hydraulic jacks were interconnected such that the same load was applied by each jack; the pressure was increased with a hand pump. A combination of wooden wedges and bagged fast-setting cement was used to provide a stable surface upon which to apply load to the irregular, undulating handrail surface. The locations of the three horizontal loading points (midspan and quarter points) are shown in Figure 16. The load was increased gradually, in conjunction with careful monitoring of the instrumentation to ensure that the bridge behaved as expected, up to a total of $6 \mathrm{kN}$ per prop. The load was held at its ultimate value for a short period of time, after which the hydraulic pressure was gradually released, slowly unloading the handrails. The load-deformation responses obtained from both the vertical and horizontal tests were compared with those determined from the finite element model where reasonable correlation was achieved. 


\subsection{Testing of full bridge with deck to SLS design load}

Testing of the full bridge with the deck plate welded in place is described in this sub-section. The tests were performed up to the serviceability limit state (SLS) design load prior to exhibition of the bridge at Dutch Design Week 2018, where the bridge was open to the public for the first time. Both vertical and horizontal load cases were considered. Views of the key items of instrumentation are presented in Figure 17: Figure 17(a) shows one of the four load cells that were positioned on hemispherical bearings at each corner of the bridge; Figures 17(b) and (c) show vertical and horizontal displacement transducers bearing on plates to avoid interference from the undulating surface geometry of the bridge, and Figure 17(d) shows strain gauges, attached to smoothed regions of the bridge. The horizontal load cases were similar to those described in Section 4.3, but the loads were increased to $8 \mathrm{kN}$ per prop. A view of the bridge from above, showing the locations of the horizontal loading props, is shown in Figure 18; the bridge exhibited a stiffer response (by about $20 \%$ ) with the deck plate welded in place. A graph showing the horizontal load per prop $P_{\mathrm{h}}$ versus the midspan horizontal deflection $\delta_{\mathrm{h} \text {,mid }}$ on both sides of the bridge for the inward loading case is presented in Figure 19 and compared with the results obtained from the numerical model. For the vertical loading case, a distributed load, totalling $105 \mathrm{kN}$ (approximately 10 tonnes), was applied by means of concrete blocks and water tanks. Eight cylindrical concrete blocks, with an average weight of $6.5 \mathrm{kN}$, were lifted onto the deck and pulled into position using a pulley system. Five empty $1 \mathrm{~m}^{3}$ water tanks were subsequently placed onto the deck (see Figures 20 and 21) and water was pumped into all tanks simultaneously to increase the applied load; upon reaching the desired load the water was then siphoned out of the water tanks after a short pause, gradually unloading the bridge, followed by the removal of the concrete blocks. The midspan bending moment $M_{\text {mid }}$ versus vertical deflection $\delta_{\mathrm{v} \text {,mid }}$ response of the bridge is compared with that obtained from the numerical model in Figure 22. The SLS load test confirmed the ability of the bridge to carry the 
level of applied load that it would be expected to experience in service, though a final series of tests is still planned in which the applied loading will be increased to the full factored design load.

\section{FINITE ELEMENT SIMULATION}

Finite element (FE) modelling of the full bridge was employed in parallel with the testing programme. The developed numerical model enabled further insight to be gained into the structural response and load-bearing capacity of the bridge and was also used to inform the location of instrumentation for the testing and subsequent long-term structural health monitoring. The FE model was developed using the FE package Abaqus [25].

Accurate replication of the geometry of the bridge was achieved by importing a 3D CAD mesh model created in Rhinoceros [22] into Abaqus [25] and assigning the measured material thicknesses determined by laser scanning of the tensile coupons. Reductions were made to the polygon count in the CAD mesh model, aiming at improving computational efficiency while retaining the key geometrical features of the bridge. Overall, an $80 \%$ mesh reduction was adopted.

The FE model comprised five main components: the 3D printed stainless steel handrails, internal stiffeners and substructure beams, and the conventionally fabricated stainless steel end beams and deck plate. The above components were connected using TIE constraints [25] to simulate continuity at the positions of manually welded intersections. A exploded view of the finite element model illustrating the constituent components is presented in Figure 23. Note that the four swirls at each corner of the bridge, which can be seen in Figure 1, were added to the bridge after testing and were therefore omitted from the presented numerical simulations. 
The scale of the MX3D bridge coupled with its high geometric complexity presented challenges in defining the finite element mesh. A mesh comprising 500000 elements was adopted, providing a balance between an accurate representation of the key geometrical features and computational efficiency. Four-noded quadrilateral shell elements with reduced integration and hourglass control, denoted S4R [25], were employed to model the substructure, deck and end support beams, while linear triangular shell elements, denoted S3 [25], were used to model the handrails and internal stiffeners, due to the geometric versatility of the latter element type allowing the more intricate geometrical features to be captured.

The measured material stress-strain characteristics of the as-built coupons were represented by the two-stage Ramberg-Osgood model and input into Abaqus in the form of true stress and strain, while material anisotropy was accounted for, both in the elastic and plastic material range, through use of the *LAMINA and *POTENTIAL keywords [25] respectively. Residual stresses and material defects, beyond those implicitly incorporated in the tensile coupon specimens, were not accounted for in the numerical simulations. A comparison of the horizontal load per prop versus the midspan horizontal deflection responses on both sides of the bridge from the test and FE model is shown in Figure 19, while the midspan bending moment versus vertical deflection responses are compared in Figure 22. The distribution of vertical deflections from the finite element simulation at the maximum test load is shown in Figure 24. The finite element results follow the trends observed in the physical testing, yielding accurate predictions of the experimental results.

\section{INITIAL VERIFICATION}

Owing both to its complex undulating geometry and non-standardised material properties, the bridge lies outside the scope of current structural design codes. This placed greater reliance on the physical testing and advanced nonlinear finite element modelling described above to verify the 
structural performance of the bridge. At the same time, by making suitable simplifications and assumptions, a more traditional analysis and design approach was also possible, with the results from the component tests confirming that the general response of the $3 \mathrm{D}$ printed elements is similar to that exhibited by conventional structural steelwork. This involved creating a beam finite element model of the bridge that captured the key features of the structural behaviour, followed by structural design checks where the bridge was considered as a U-frame. The beam finite element model, developed by Arup, corroborated the shell finite element results obtained by the authors.

The physical testing to date has shown that the bridge can sustain its full serviceability limit state design load, while the nonlinear finite element simulations and simplified design checks indicated that further reserves in load-carrying capacity are also available. This initial verification enabled to the bridge to be unveiled to the public, with controlled access, for Dutch Design Week 2018. Further testing, up to ultimate limit state design load levels and modelling is planned before the bridge is placed in its final location and fully opened to the public.

\section{CONCLUSIONS}

Testing, simulation and initial verification of the MX3D bridge has been described in this paper. The bridge, which is the first of its kind, was 3D printed from stainless steel using the wire and arc additive manufacturing (WAAM) technique. To support the safety verification of the bridge, a series of material, component and full-scale structural testing has been carried out by the authors. The full-scale bridge testing was carried out at various stages throughout the bridge construction, and it has been demonstrated to date that the bridge can carry its full serviceability limit state design load. This initial verification enabled to the bridge to be unveiled to the public, with controlled access, for Dutch Design Week 2018, with further testing and modelling planned before the bridge is placed in its final location and fully opened to the public. The presented approach of 
comprehensive testing and modelling is deemed necessary for the safety verification of bespoke large-scale civil engineering structures fabricated using this new technology, at least in the short to medium term, as sophisticated inline quality control measures and standards are developed.

\section{ACKNOWLEDGEMENTS}

The research presented in this paper was possible thanks to funding and support from Engineering and Physical Sciences Research Council (EPSRC) and the Lloyd's Register Foundation funded Data Centric Engineering programme at the Alan Turing Institute (ATI). The authors would like to acknowledge the ingenuity and assistance of MX3D and Arup in the bridge testing programme. The assistance of the technicians at Imperial College London, as well as Anna Schumacher, Kwan Lui and Wing Wan, to the testing programme are also gratefully acknowledged.

\section{REFERENCES}

[1] Buchanan, C. and Gardner, L. Metal 3D printing in construction: a review of methods, research, applications, opportunities and challenges, Engineering Structures, 180, 332-348, 2019.

[2] Buchanan, C., Matilainen, V. P., Salminen, A. and Gardner, L. Structural performance of additive manufactured metallic material and cross-sections, Journal of Constructional Steel Research, 136, 35-48, 2017.

[3] Yan, J. J., Chen, M. T., Quach, W. M. and Young, B. Mechanical properties and crosssectional behavior of additively manufactured high strength steel tubular sections, ThinWalled Structures, 144, 106158, 2019.

[4] Laghi, V., Palermo, M., Gasparini, G., Girelli, V. A. and Trombetti, T. Experimental results for structural design of Wire-and-Arc Additive Manufactured stainless steel members, Journal of Constructional Steel Research, 2019 [In press] 
[5] Laghi, V., Palermo, M., Tonelli, L., Gasparini, G., Ceschini, L. and Trombetti, T. Tensile properties and microstructural features of $304 \mathrm{~L}$ austenitic stainless steel produced by wireand-arc additive manufacturing, The International Journal of Advanced Manufacturing Technology, 106, 3693-3705, 2020.

[6] Camacho, D. D., Clayton, P., O'Brien, W. J., Seepersad, C., Juenger, M., Ferron, R. and Salamone, S. Applications of additive manufacturing in the construction industry - A forward-looking review, Automation in Construction, 89, 110-119, 2018.

[7] Haden, C. V., Zeng, G., Carter III, F. M., Ruhl, C., Krick, B. A. and Harlow, D. G. Wire and arc additive manufactured steel: Tensile and wear properties, Additive Manufacturing, 16, 115-123, 2017.

[8] Gordon, J. V., Haden, C. V., Nied, H. F., Vinci, R. P. and Harlow, D. G. Fatigue crack growth anisotropy, texture and residual stress in austenitic steel made by wire and arc additive manufacturing, Materials Science and Engineering: A, 724, 431-438, 2018.

[9] Williams, S. W., Martina, F., Addison, A. C., Ding, J., Pardal, G. and Colegrove, P., Wire + Arc Additive Manufacturing. Materials Science and Technology, 32(7), 641-647, 2016.

[10] Kyvelou, P., Slack, H., Daskalaki Mountanou, D., Wadee, A. M., Britton, B. T., Buchanan, C. and Gardner, L. Mechanical and microstructural testing of wire and arc additively manufactured sheet material, Materials and Design, 192, 108675, 2020.

[10] EN ISO 6892-1. Metallic materials - Tensile testing - Part 1: Method of test at room temperature., CEN (European Committee for Standardization), Brussels, Belgium, 2009.

[11] Ramberg, W. and Osgood, W. R. Description of stress-strain curves by three parameters, Technical Note No. 902, National Advisory Committee for Aeronautics, Washington, D.C., USA, 1943. 
[12] Hill, H.N. Determination of stress-strain relations from offset yield strength values, Technical Note No. 927, National Advisory Committee for Aeronautics, Washington, D.C., USA, 1944.

[13] Mirambell, E. and Real, E. On the calculation of deflections in structural stainless steel beams: an experimental and numerical investigation, Journal of Constructional Steel Research, 54(1), 109-133, 2000.

[14] Rasmussen, K. J. R. Full-range stress-strain curves for stainless steel alloys, Journal of Constructional Steel Research, 59(1), 47-61, 2003.

[15] Gardner, L. and Ashraf, M. Structural design for non-linear metallic materials, Engineering Structures, 28(6), 926-934, 2006.

[16] Arrayago, I., Real, E. and Gardner, L. Description of stress-strain curves for stainless steel alloys, Materials and Design, 87, 540-552, 2015.

[17] Gardner, L. and Yun, X. Description of stress-strain curves for cold-formed steels, Construction and Building Materials. 189, 527-538, 2018.

[18] EN 1993-1-4. Eurocode 3: Design of Steel Structures - Part 1-4: General Rules Supplementary Rules for Stainless Steels, European Committee for Standardization (CEN), Brussels, 2006.

[19] Ibrahim, A., Mahmoud, E., Yamin, M. and Patibandla, V. C. Experimental study on Portland cement pervious concrete mechanical and hydrological properties, Construction and Building Materials, 50, 524-529, 2014.

[20] Geomagic Wrap. 3D Systems Inc., 2017.

[21] Rhinoceros 3D. Robert McNeel \& Associates, 2017. 
[22] Wang, J., Afshan, S., Schillo, N., Theofanous, M., Feldmann, M. and Gardner, L. Material properties and compressive local buckling response of high strength steel square and rectangular hollow sections, Engineering Structures, 130, 297-315, 2017.

[23] Centre for Advanced Structural Engineering. Compression tests of stainless steel tubular columns, Investigation report S770, University of Sydney, 1990.

[24] Abaqus/CAE 2016. Dassault Systèmes Simulia Corp, 2015. 
Table 1: Summary of average measured material properties of machined tensile coupons by direction of testing relative to the print layer orientation [10].

\begin{tabular}{cccccccccc}
\hline $\begin{array}{c}\theta \\
\left({ }^{\circ}\right)\end{array}$ & $\begin{array}{c}E \\
\left(\mathrm{~N} / \mathrm{mm}^{2}\right)\end{array}$ & $\begin{array}{c}\sigma_{0.2} \\
\left(\mathrm{~N} / \mathrm{mm}^{2}\right)\end{array}$ & $\begin{array}{c}\sigma_{1.0} \\
\left(\mathrm{~N} / \mathrm{mm}^{2}\right)\end{array}$ & $\begin{array}{c}\sigma_{\mathrm{u}} \\
\left(\mathrm{N} / \mathrm{mm}^{2}\right)\end{array}$ & $\begin{array}{c}\varepsilon_{\mathrm{u}} \\
(\%)\end{array}$ & $\begin{array}{c}\varepsilon_{\mathrm{f}} \\
(\%)\end{array}$ & $n$ & $m_{1.0}$ & $m_{\mathrm{u}}$ \\
\hline 0 & 143300 & 356 & 382 & 575 & 30.7 & 39.7 & 15.8 & 1.7 & 2.4 \\
45 & 219500 & 407 & 437 & 626 & 36.4 & 40.5 & 13.6 & 2.0 & 2.4 \\
90 & 139600 & 338 & 381 & 554 & 29.7 & 40.3 & 6.8 & 2.3 & 2.7 \\
\hline
\end{tabular}

Table 2: Summary of average measured effective material properties of as-built tensile coupons by direction of testing relative to the print layer orientation [10].

\begin{tabular}{cccccccccc}
\hline $\begin{array}{c}t_{\text {nom }} \\
(\mathrm{mm})\end{array}$ & $\begin{array}{c}\theta \\
\left({ }^{\circ}\right)\end{array}$ & $\begin{array}{c}E \\
\left(\mathrm{~N} / \mathrm{mm}^{2}\right)\end{array}$ & $\begin{array}{c}\sigma_{0.2} \\
\left(\mathrm{~N} / \mathrm{mm}^{2}\right)\end{array}$ & $\begin{array}{c}\sigma_{1.0} \\
\left(\mathrm{~N} / \mathrm{mm}^{2}\right)\end{array}$ & $\begin{array}{c}\sigma_{\mathrm{u}} \\
\left(\mathrm{N} / \mathrm{mm}^{2}\right)\end{array}$ & $\begin{array}{c}\varepsilon_{\mathrm{u}} \\
(\%)\end{array}$ & $n$ & $m_{1.0}$ & $m_{\mathrm{u}}$ \\
\hline \multirow{3}{*}{3.5} & 0 & 135900 & 333 & 362 & 553 & 27.3 & 15.5 & 1.8 & 2.2 \\
& 45 & 192600 & 344 & 391 & 570 & 25.5 & 9.4 & 2.4 & 2.3 \\
& 90 & 90200 & 261 & 319 & 448 & 11.9 & 6.5 & 2.5 & 2.6 \\
\hline \multirow{3}{*}{8.0} & 0 & 137100 & 325 & 349 & 535 & 32.5 & 22.9 & 1.8 & 2.4 \\
& 45 & 201200 & 351 & 391 & 559 & 25.5 & 11.5 & 2.3 & 2.3 \\
& 90 & 109100 & 271 & 326 & 423 & 10.3 & 5.5 & 2.6 & 2.5 \\
\hline
\end{tabular}


Table 3: Summary of CHS stub column test results

\begin{tabular}{lccccccc}
\hline CHS specimen & $\begin{array}{c}\text { EC3 } \\
\text { class }\end{array}$ & $D / t \varepsilon^{2}$ & $\begin{array}{c}N_{\mathrm{u}} \\
(\mathrm{kN})\end{array}$ & $\begin{array}{c}\delta_{\mathrm{u}, \mathrm{LVDT}} \\
(\mathrm{mm})\end{array}$ & $\begin{array}{c}\delta_{\mathrm{u}, \mathrm{DIC}} \\
(\mathrm{mm})\end{array}$ & $N_{\mathrm{u}} / N_{\mathrm{y}}$ & $\begin{array}{c}N_{\mathrm{u}} / \\
N_{\mathrm{u}, \mathrm{EC} 3}\end{array}$ \\
\hline $105 \times 8-355-\mathrm{F}$ & 1 & 32.4 & 943.8 & 37.91 & 35.98 & 1.34 & 1.34 \\
$105 \times 8-355-\mathrm{FR}$ & 1 & 32.9 & 732.8 & 19.84 & 20.71 & 1.09 & 1.09 \\
$170 \times 3.5-580-\mathrm{F}$ & 4 & 99.9 & 530.3 & 4.07 & 4.29 & 0.82 & 0.86 \\
$170 \times 3.5-580-\mathrm{FR}$ & 4 & 103.8 & 563.5 & 4.48 & 4.38 & 0.87 & 0.94 \\
\hline
\end{tabular}

Table 4: Summary of SHS stub column test results

\begin{tabular}{lccccccc}
\hline SHS specimen & $\begin{array}{c}\text { EC3 } \\
\text { class }\end{array}$ & $c / t \varepsilon$ & $\begin{array}{c}N_{\mathrm{u}} \\
(\mathrm{kN})\end{array}$ & $\begin{array}{c}\delta_{\mathrm{u}, \mathrm{LVDT}} \\
(\mathrm{mm})\end{array}$ & $\begin{array}{c}\delta_{\mathrm{u}, \mathrm{DIC}} \\
(\mathrm{mm})\end{array}$ & $N_{\mathrm{u}} / N_{\mathrm{y}}$ & $\begin{array}{c}N_{\mathrm{u}} / \\
N_{\mathrm{u}, \mathrm{EC} 3}\end{array}$ \\
\hline $120 \times 120 \times 8-450-\mathrm{F}$ & 1 & 21.8 & 994.2 & 9.03 & 8.83 & 1.03 & 1.03 \\
$120 \times 120 \times 8-450-\mathrm{FR}$ & 1 & 23.0 & 842.3 & 6.33 & 6.43 & 0.91 & 0.91 \\
$130 \times 130 \times 3.5-500-\mathrm{F}$ & 4 & 47.2 & 437.7 & 1.99 & 2.16 & 0.70 & 0.86 \\
$130 \times 130 \times 3.5-500-\mathrm{FR}$ & 4 & 46.8 & 414.5 & 1.84 & 1.84 & 0.66 & 0.81 \\
\hline
\end{tabular}




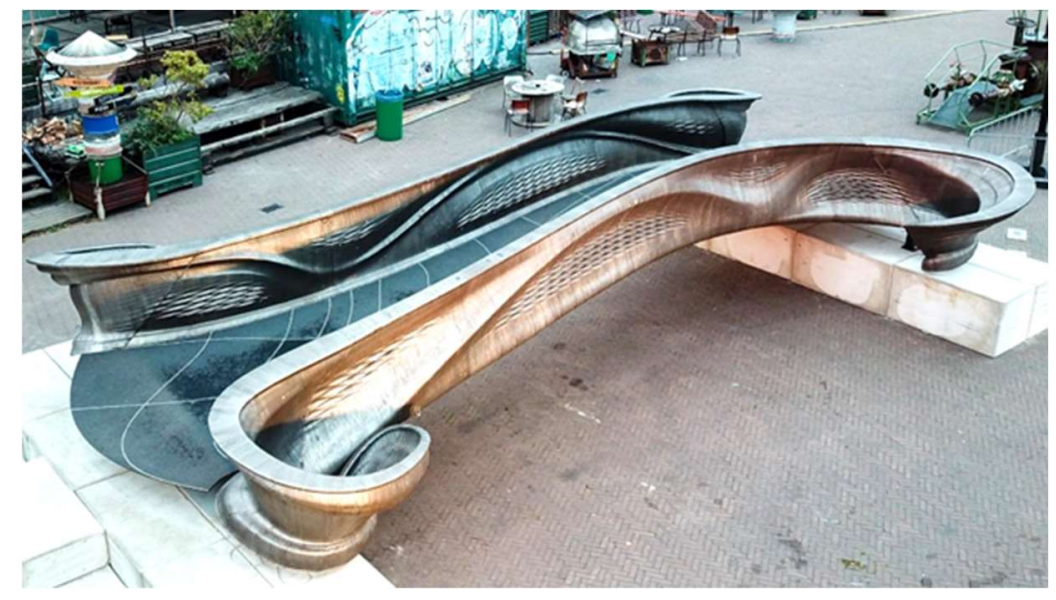

Figure 1: Overall view of MX3D metal 3D printed footbridge

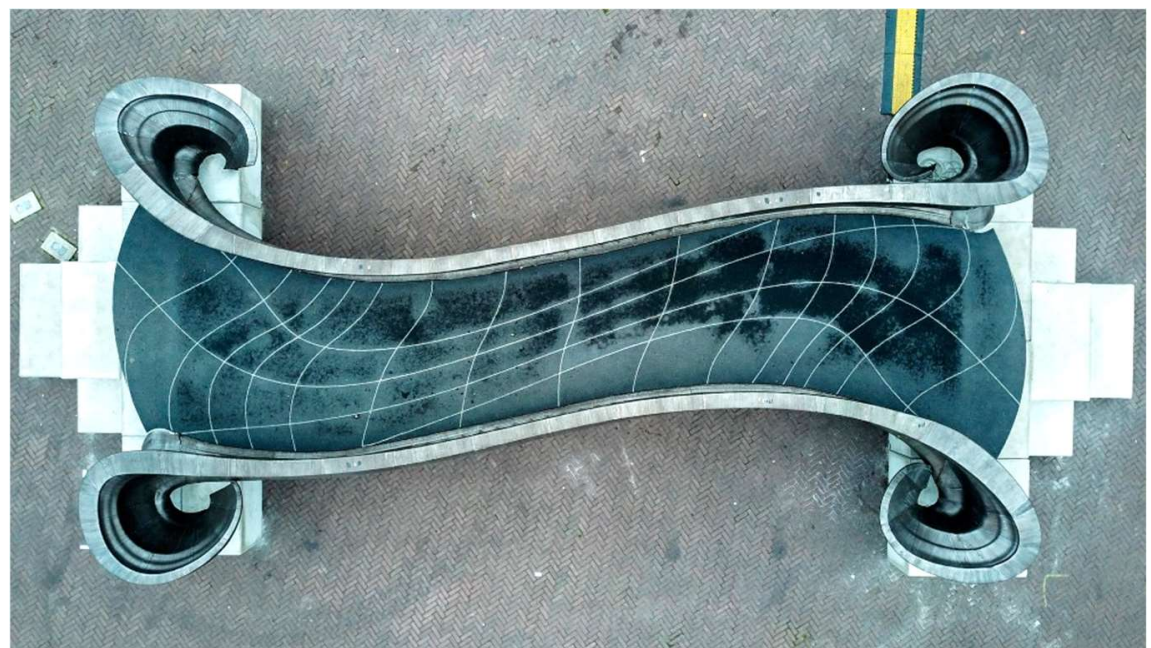

Figure 2: Plan view of MX3D metal 3D printed footbridge 

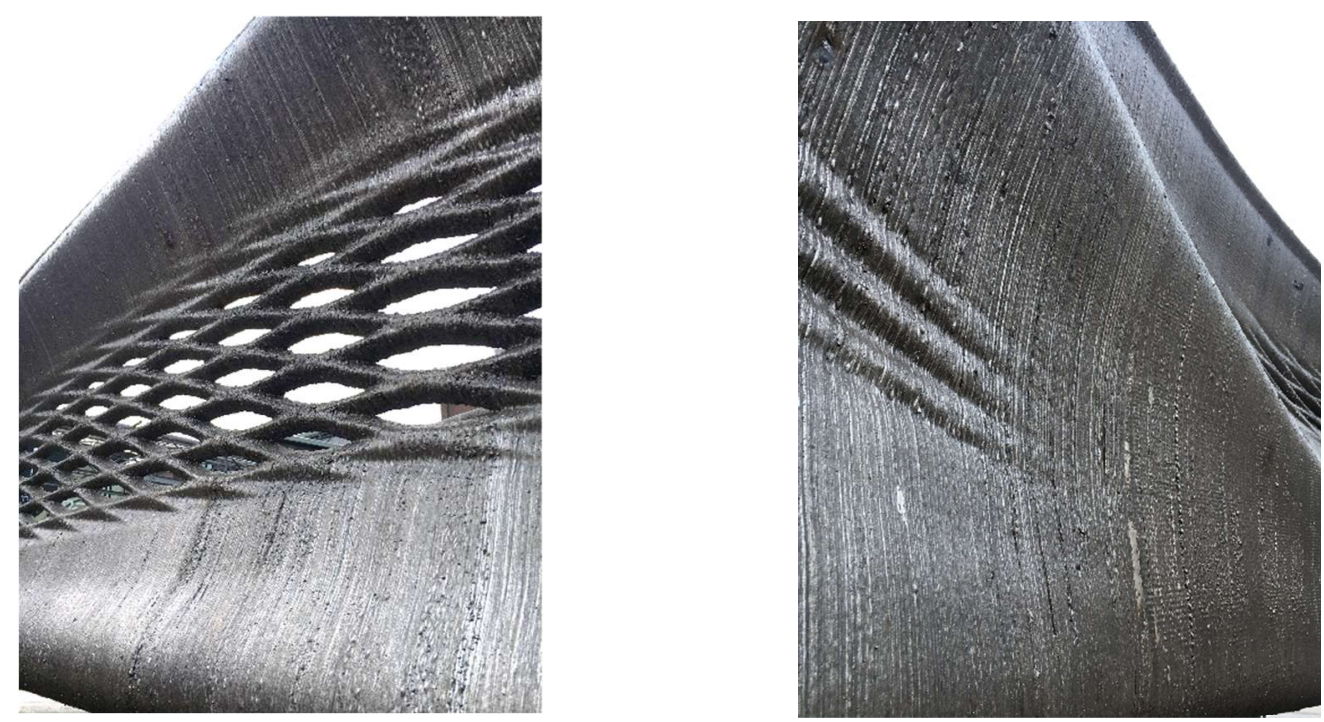

Figure 3: View of metal 3D printed bridge emphasizing layers of printed material running perpendicular to the longitudinal axis of the bridge

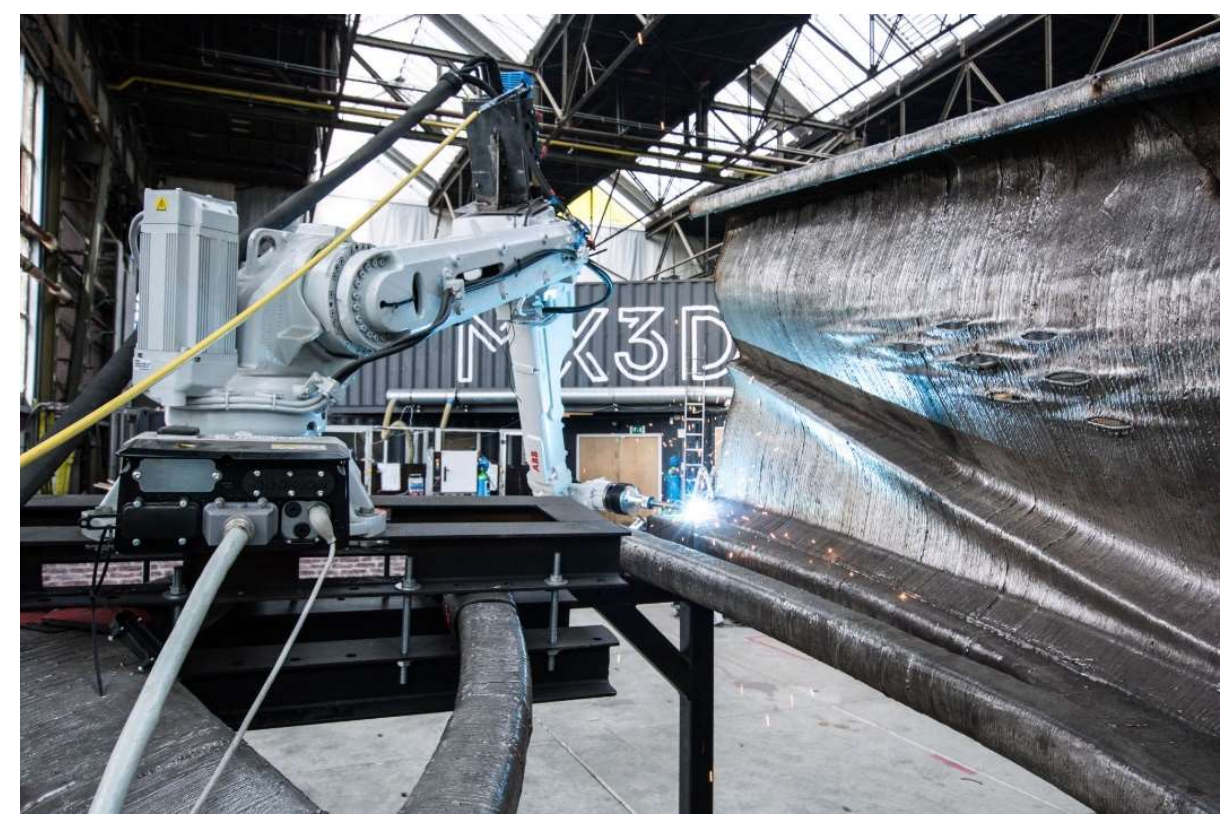

Figure 4: Printing of MX3D bridge, with robot mounted on bridge for demonstration purposes 

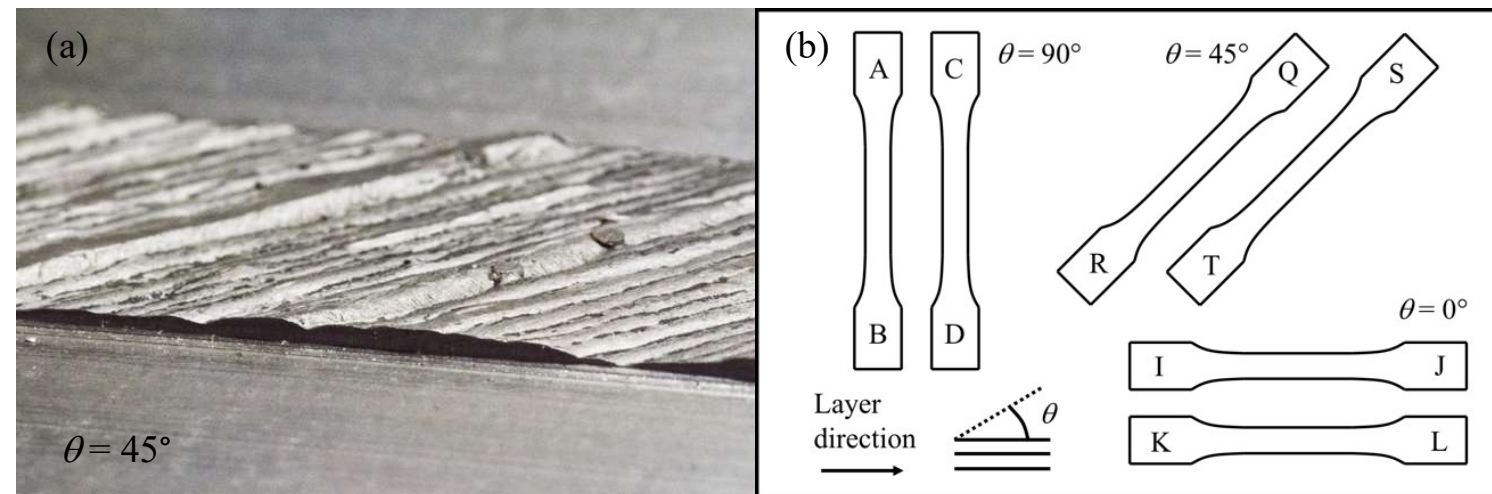

Figure 5: (a) As-built (AB) and machined (M) surfaces on a WAAM plate and (b) orientation of coupons.

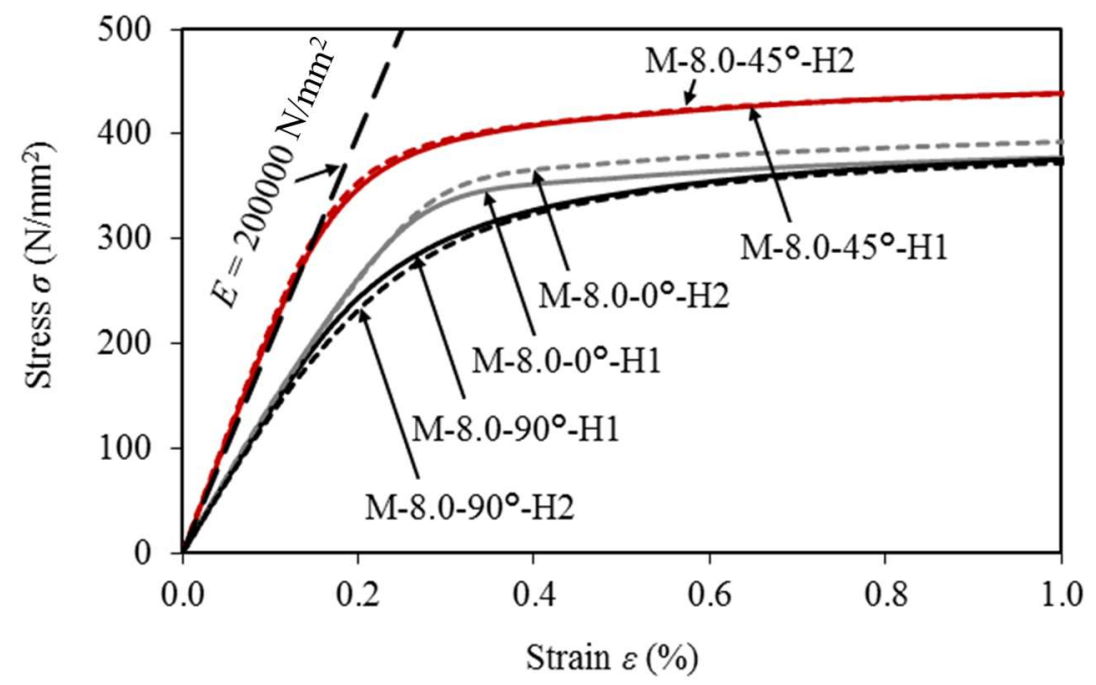

Figure 6: Measured stress-strain curves from typical fully machined WAAM tensile coupon tests. 


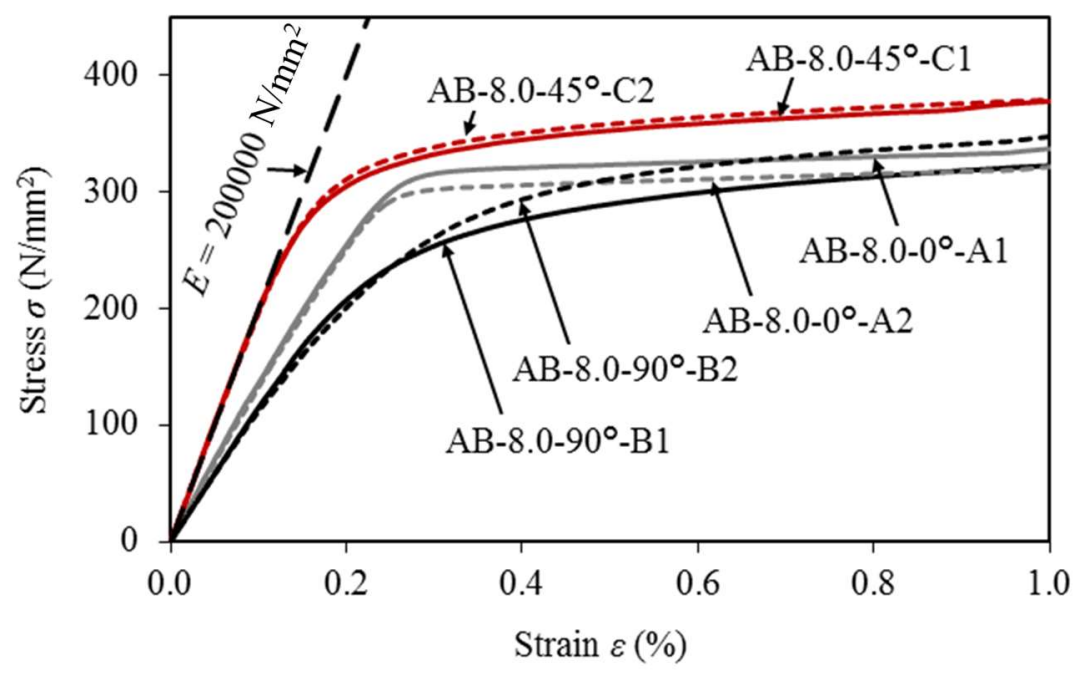

Figure 7: Measured effective stress-strain curves from typical as-built WAAM tensile coupon tests.

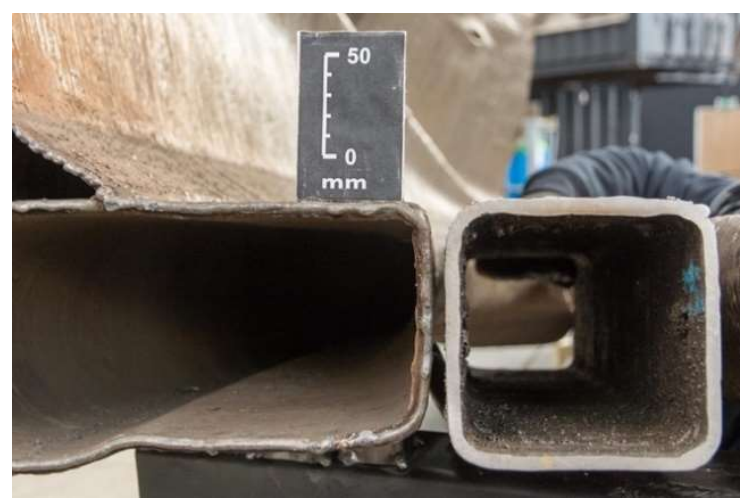

Figure 8: A $120 \times 120 \times 8$ SHS next to its corresponding part of the substructure of the MX3D bridge. 

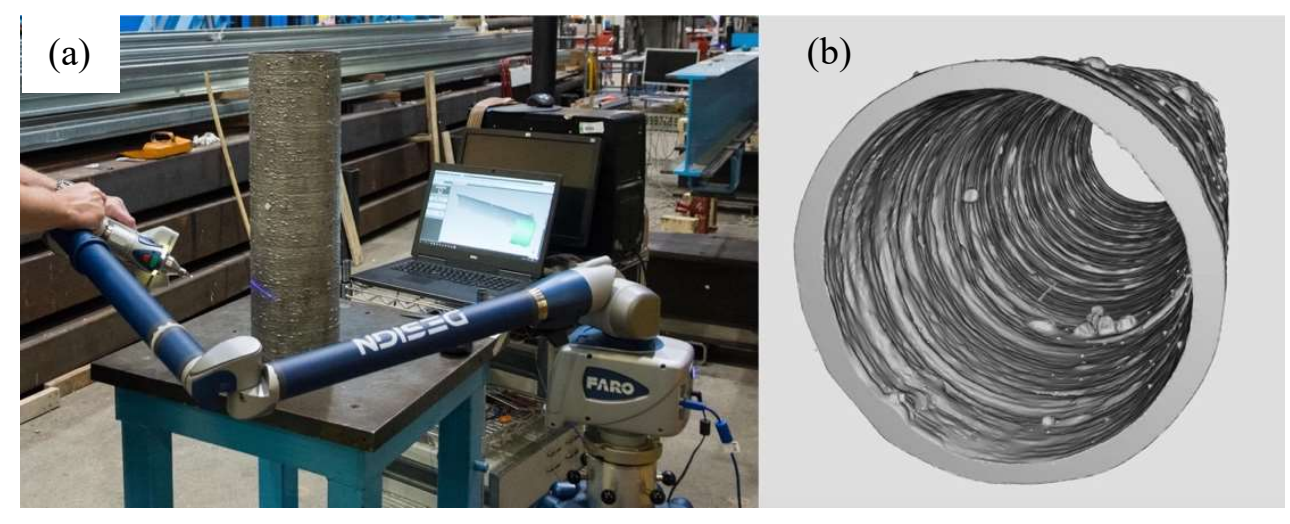

Figure 9: (a) Laser scanning a 170×3.5 CHS specimen and (b) a merged laser scan.

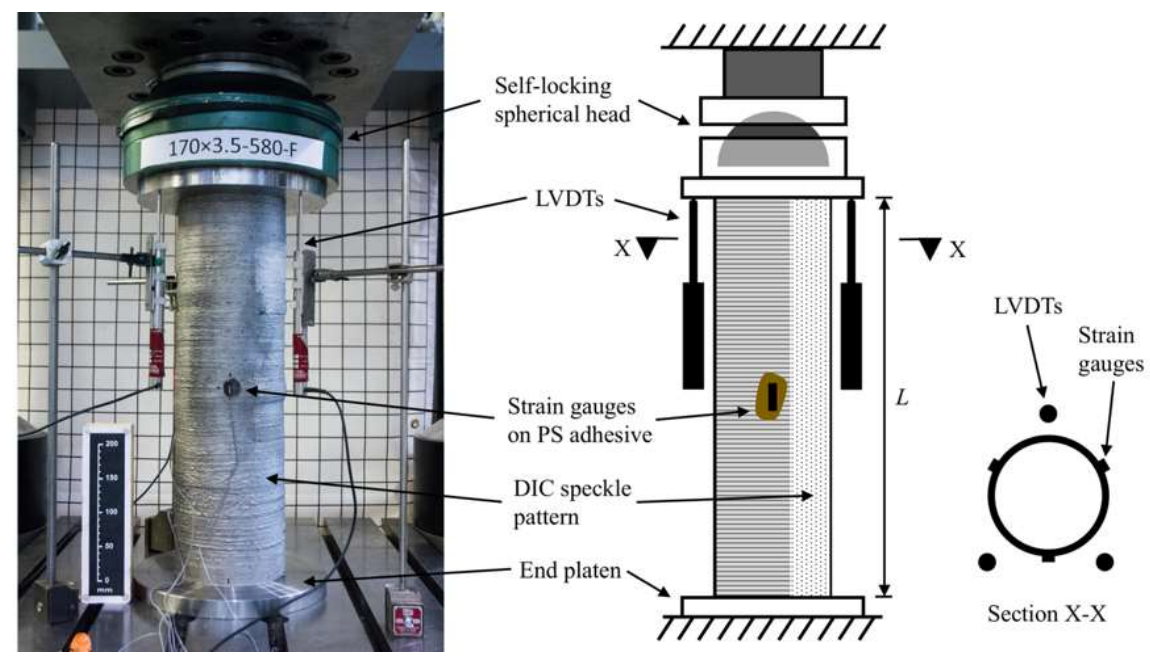

Figure 10: Test setup for the CHS stub columns. 

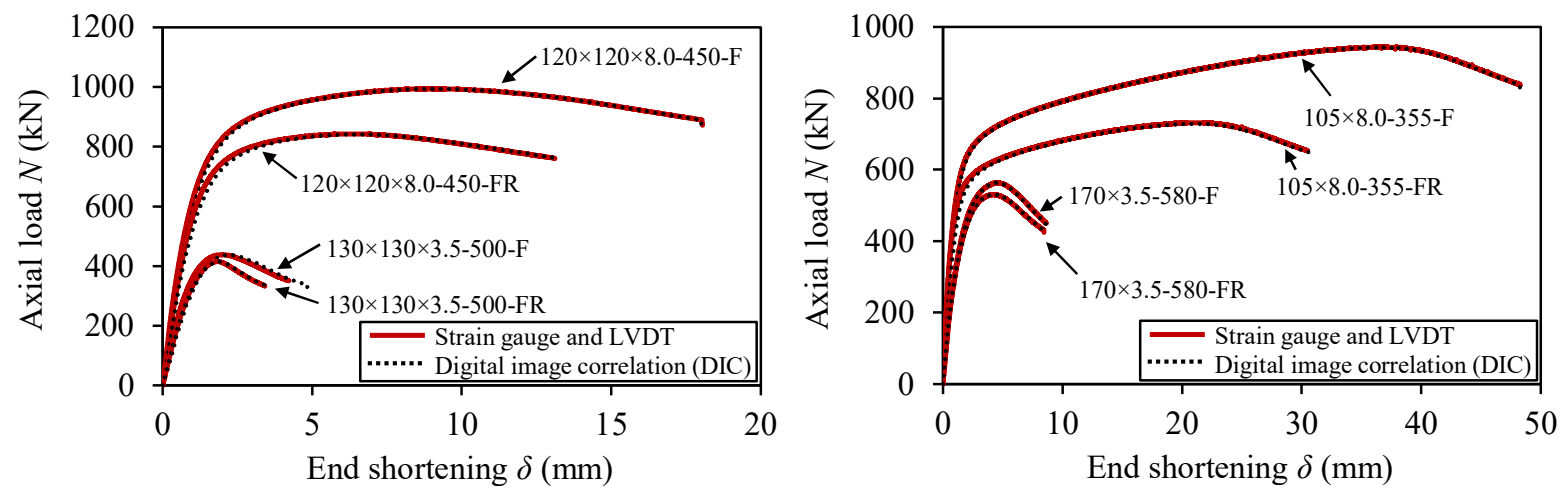

Figure 11: Measured load-end shortening curves for the (a) CHS and (b) SHS stub columns.

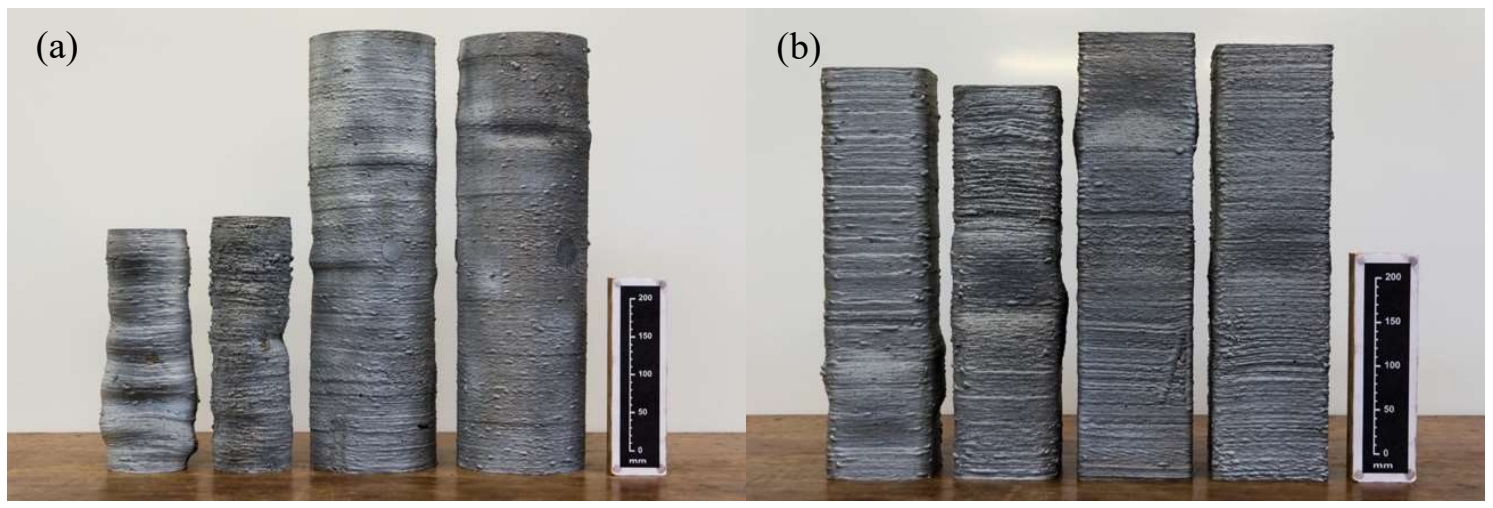

Figure 12: From left to right, (a) deformed 105×8-355-F, 105 $\times 8-355-\mathrm{FR}, 170 \times 3.5-580-\mathrm{F}$ and $170 \times 3.5-580$-FR CHS specimens and (b) deformed $120 \times 120 \times 8-450-\mathrm{F}, 120 \times 120 \times 8-450-\mathrm{FR}$, $130 \times 130 \times 3.5-500-\mathrm{F}$ and $130 \times 130 \times 3.5-500$-FR SHS specimens. 

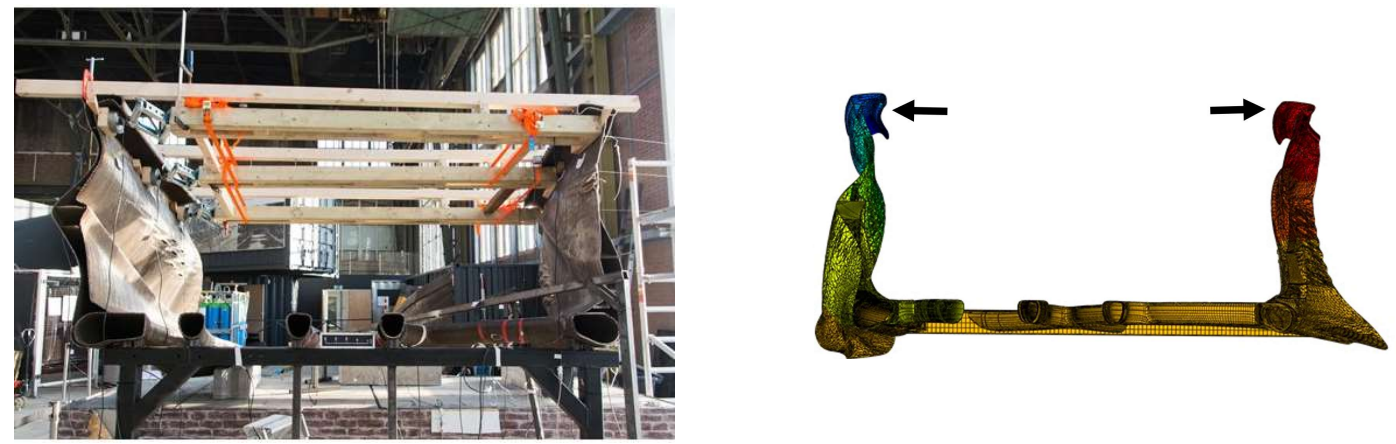

Figure 13: Overall view of testing (left) and finite element modelling (right) of first $2.4 \mathrm{~m}$ segment of bridge under horizontal loading

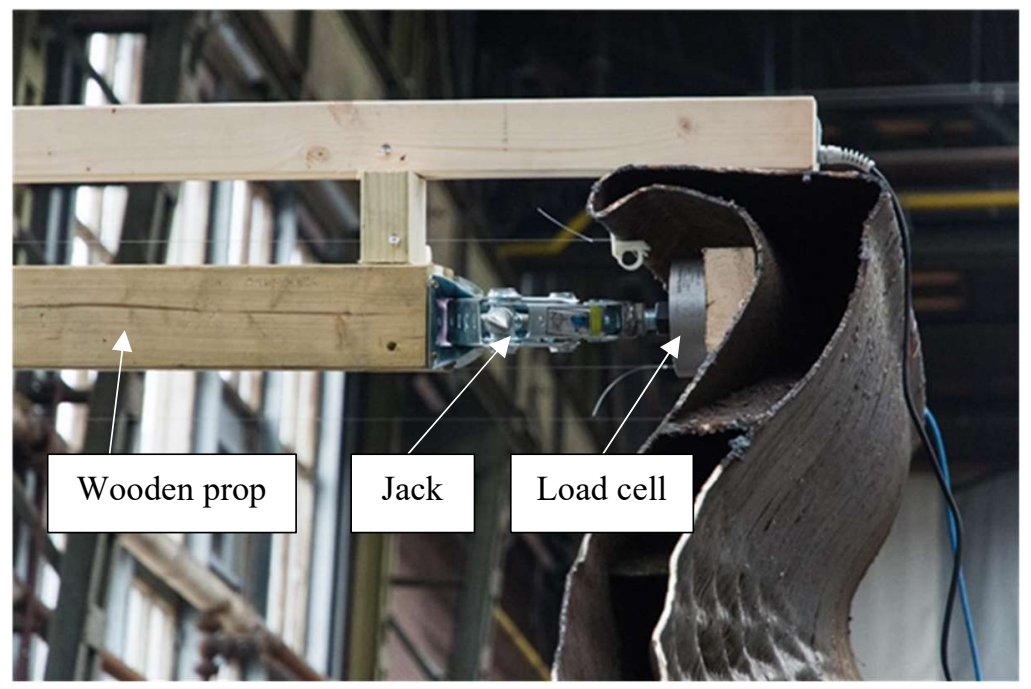

Figure 14: Wooden prop, jack and load cell employed in testing of first $2.4 \mathrm{~m}$ segment of bridge under horizontal loading 


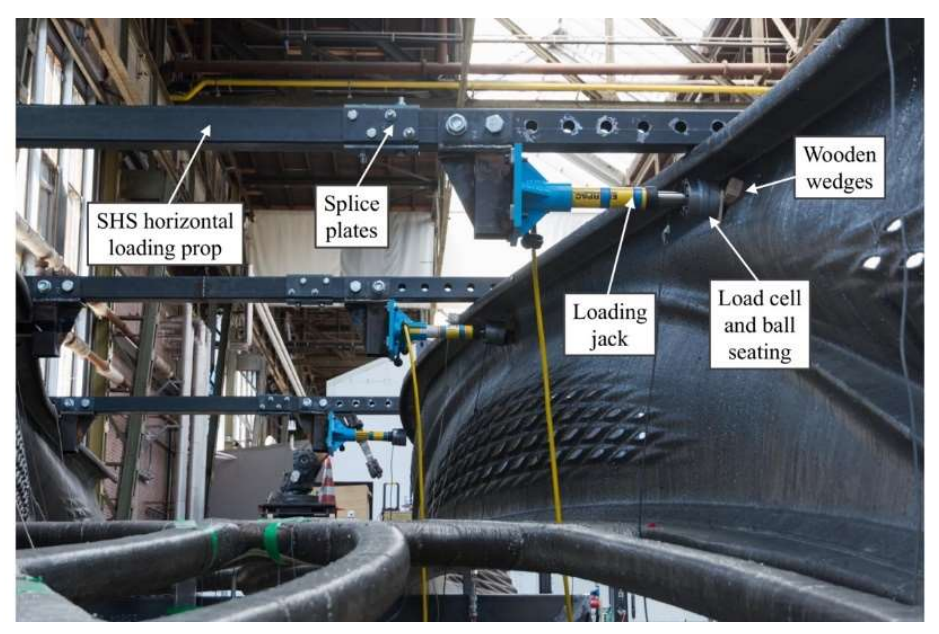

Figure 15: Horizontal loading arrangement for bridge without the deck plate in place.

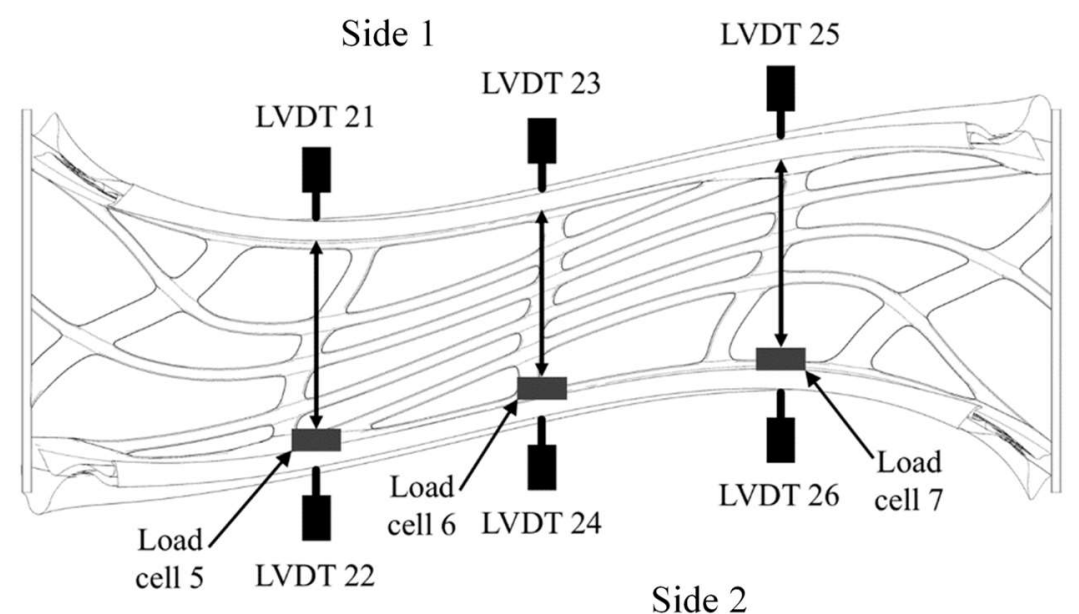

Figure 16: Plan view of the horizontal loading arrangement 

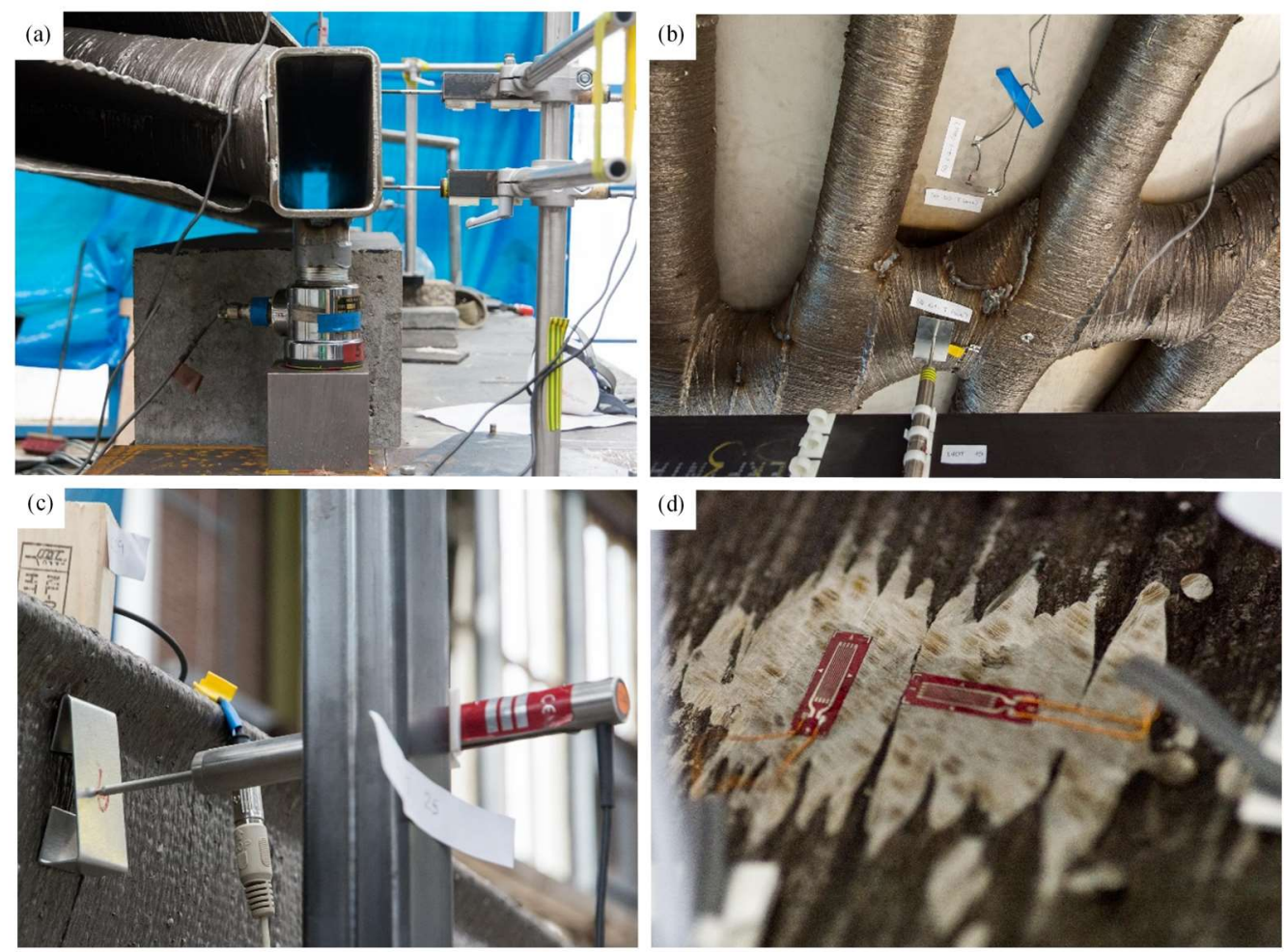

Figure 17: Views of key items of instrumentation (a) load cells, (b) vertical displacement transducers, (c) horizontal displacement transducers and (d) strain gauges

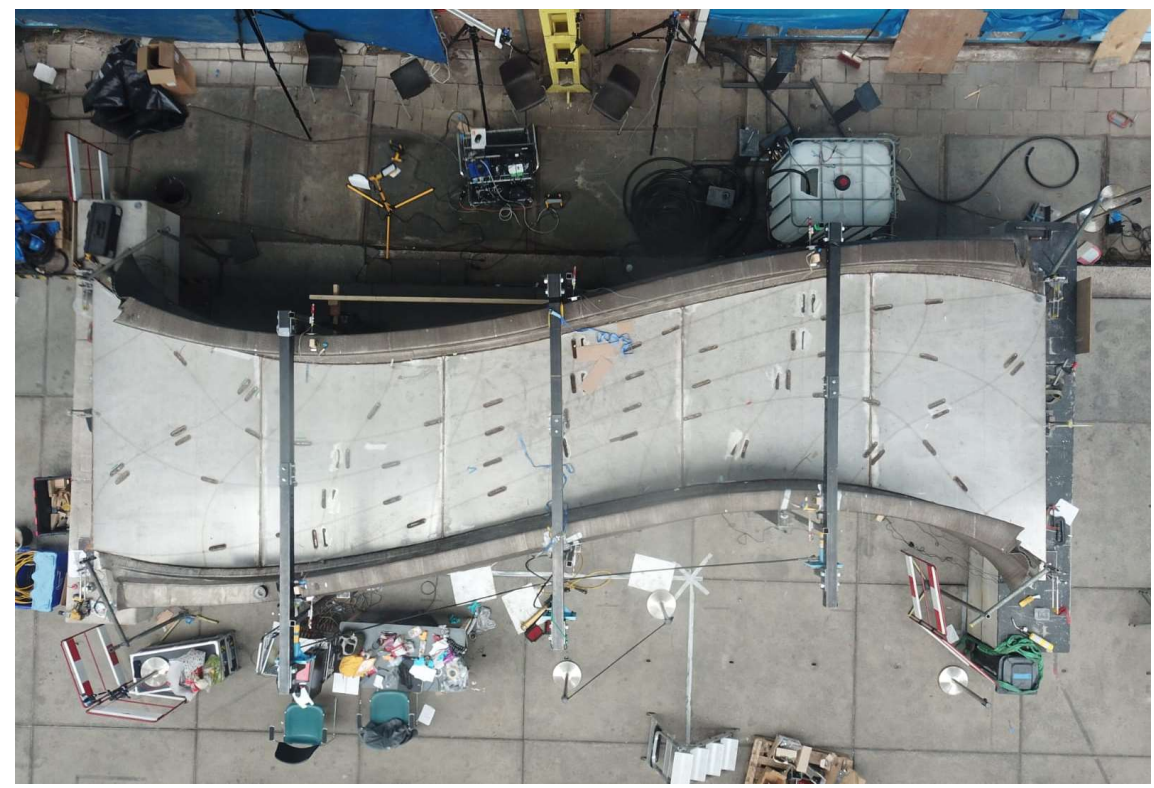

Figure 18: An overhead photograph of the horizontal loading test of the full bridge with the deck plate in place 


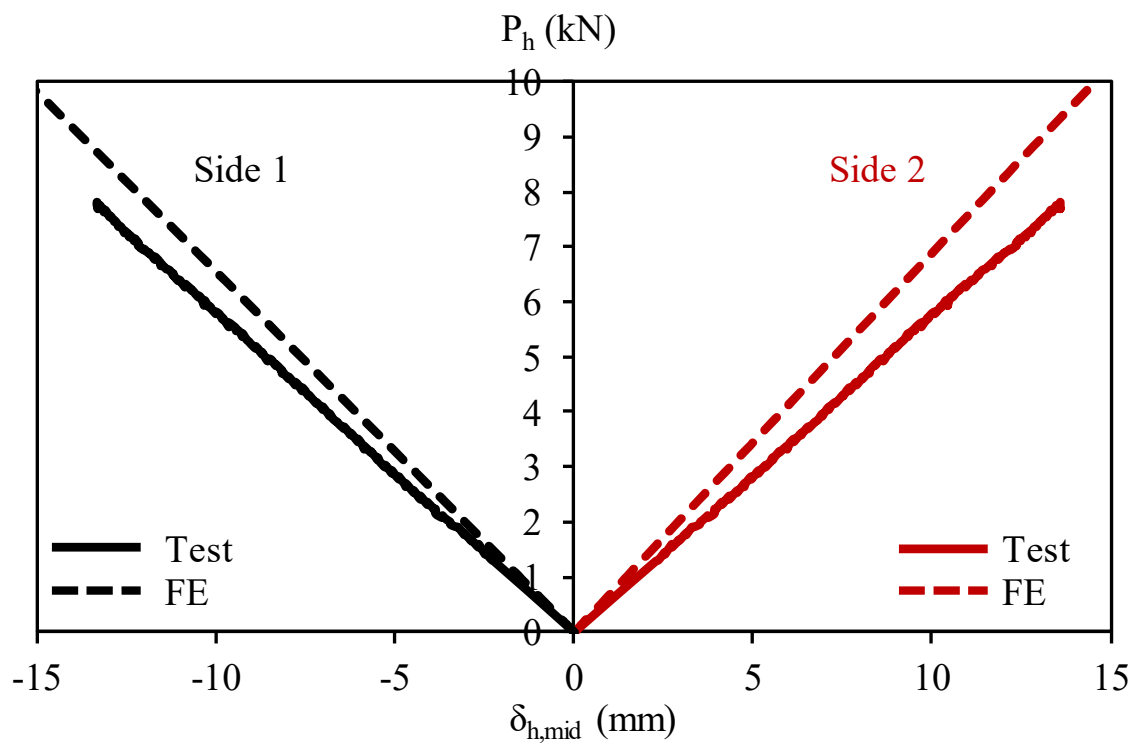

Figure 19: Horizontal prop force versus midspan horizontal deflection on both sides of the full bridge with deck, as obtained from physical testing and nonlinear finite element modelling

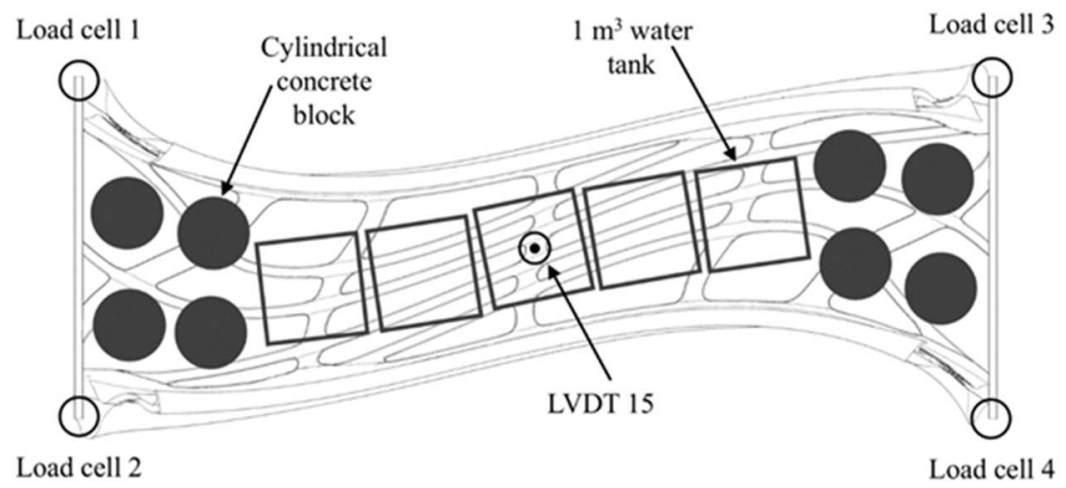

Figure 20: Plan view of the 10 tonne vertical loading test setup. 


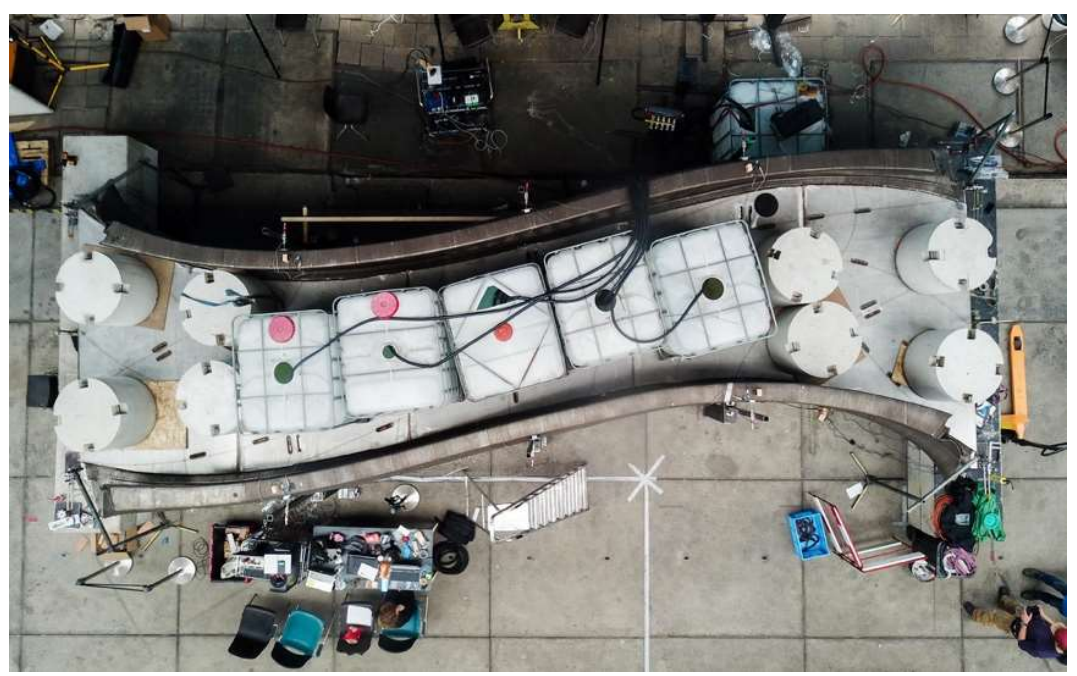

Figure 21: An overhead photograph of the 10 tonne vertical loading test with the deck plate in place.

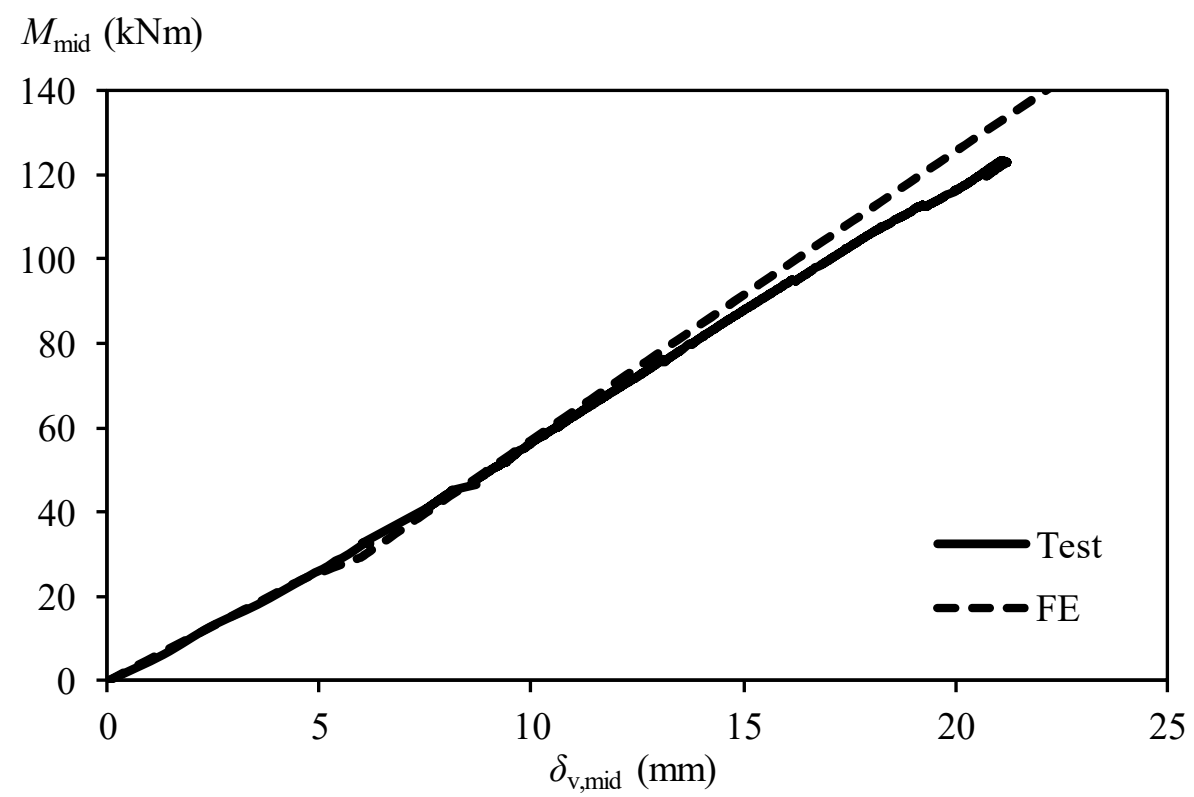

Figure 22: Midspan bending moment versus vertical deflection of the full bridge with deck, as obtained from physical testing and nonlinear finite element modelling. Note that the increase in gradient of the curve is due to the changing distribution of loading during testing. 


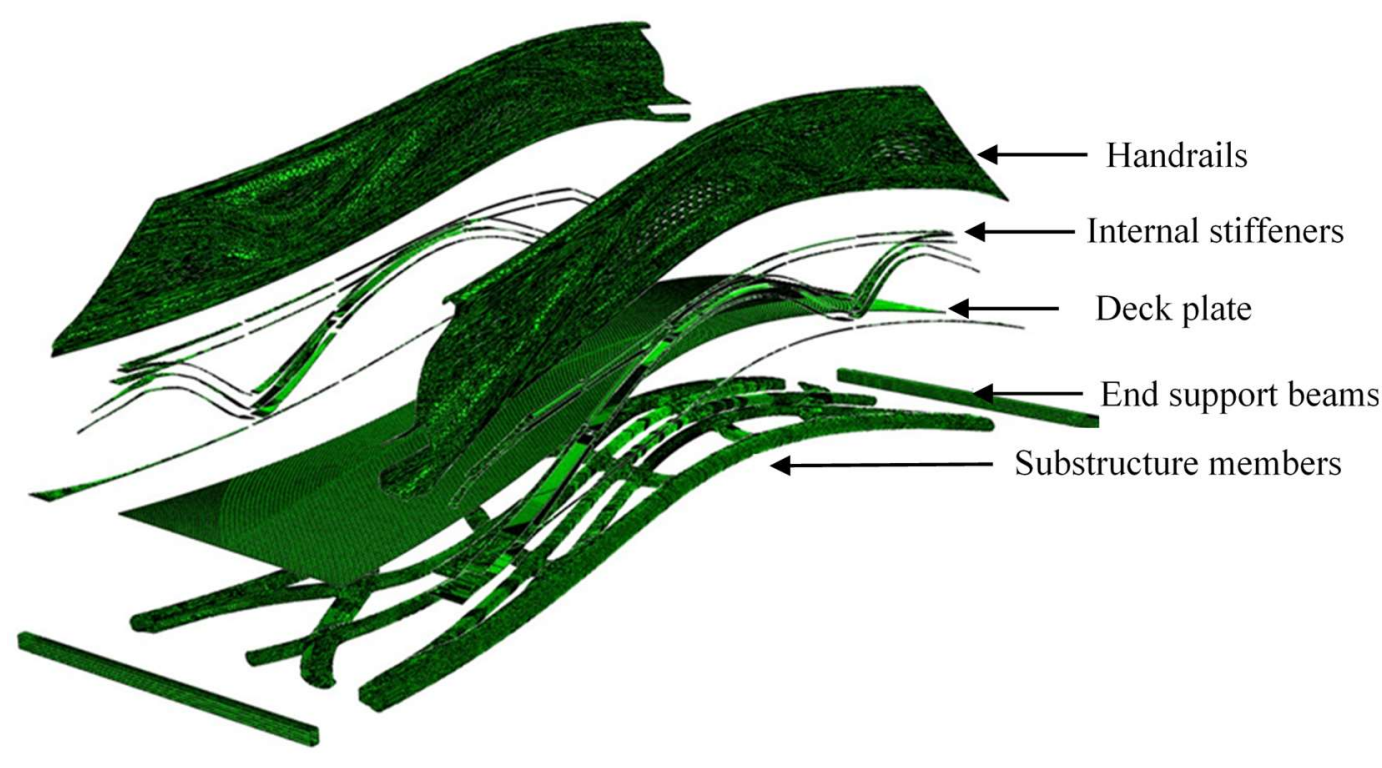

Figure 23: Exploded view of the FE model showing the constituent structural components

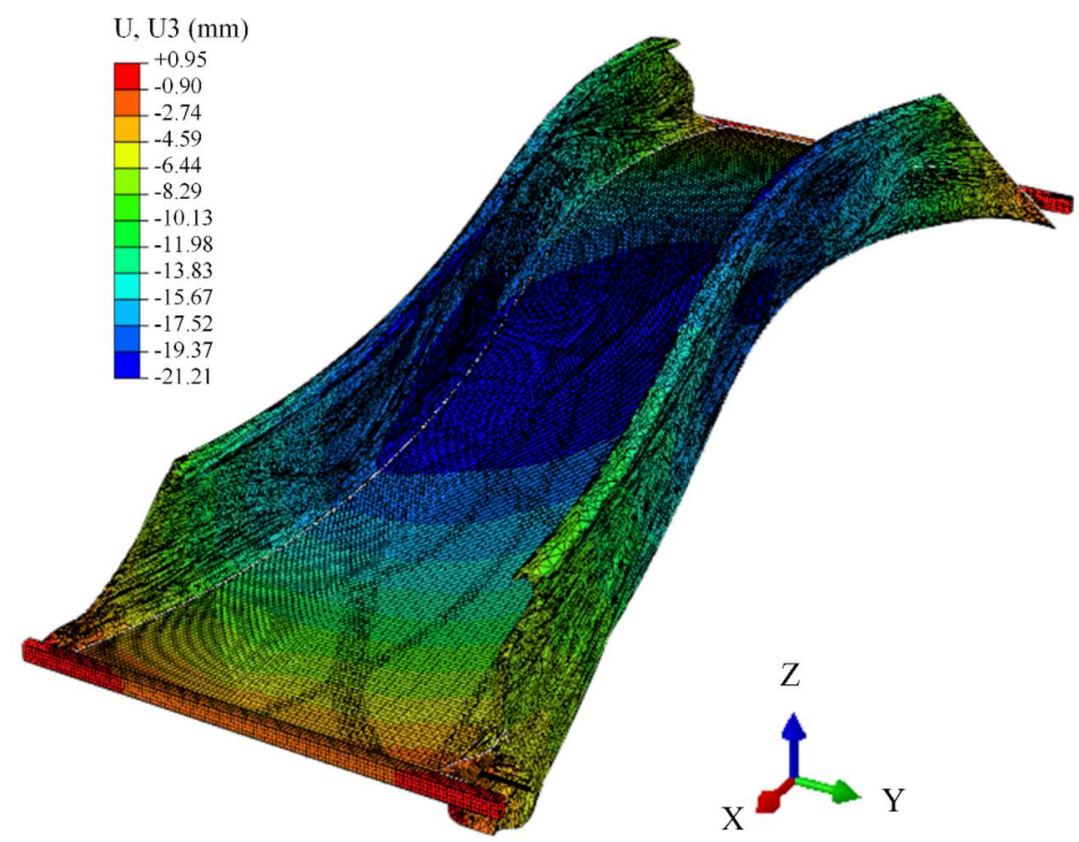

Figure 24: Distribution of vertical deflections from the finite element simulation of the bridge at the maximum test load 